\title{
EL DENOMINADO BLOQUE DE CONSTITUCIONALIDAD COMO PARÁMETRO DE INTERPRETACIÓN CONSTITUCIONAL, ¿ES NECESARIO EN EL PERÚ?
}

\begin{abstract}
Artemio Daniel MeZa Hurtado*
Resumen

El Tribunal Constitucional del Perú para cumplir con la función de máximo intérprete de la Constitución, para determinar la correcta interpretación en un caso concreto y cumplir con su principal función, de determinar la inconstitucionalidad sometida a su conocimiento, no utiliza sólo las normas contenidas en la Constitución, casi siempre, acude a otras normas y criterios, que se conocen como el parámetro de constitucionalidad o bloque de constitucionalidad, cuya necesidad o importancia se encuentra en debate.
\end{abstract}

Palabras clave: Interpretación - Inconstitucionalidad - Parámetro de constitucionalidad - Bloque de constitucionalidad.

\begin{abstract}
The Constitutional Tribunal of the Peru to fulfill the function of maximum interpreter of the Constitution, to determine the correct interpretation in a concrete case and to fulfill its main function, of determining the subjected unconstitutionality to its knowledge, doesn't only use the norms contained in the Constitution, almost always, he goes to other norms and approaches that are known as the parameter of constitutionality or block of constitutionality whose necessity or importance is in debate.
\end{abstract}

Key words: Interpretation-Unconstitutionality -Parameter of constitutionality - Block of constitutionality.

\section{Sumario}

I.- Introducción. II.- Antecedentes. III.- Definición. IV.- Tipos o clase del bloque de constitucionalidad. V.- El caso de Francia. VI.- El bloque de constitucionalidad en España. VII.- El bloque de constitucionalidad en Latinoamérica. VIII.- El parámetro de constitucionalidad en el Perú. IX.Problemas en su aplicación. X.- Conclusiones. XI.- Bibliografía.

\footnotetext{
* Juez Superior Titular de la Corte Superior de Justicia de Piura - Poder Judicial del Perú. Profesor de la Universidad Nacional de Trujillo y de la Universidad Nacional Pedro Ruiz Gallo; profesor de la Academia de la Magistratura.
} 
Artemio Daniel Meza Hurtado - El denominado bloque de constitucionalidad como parámetro de interpretación constitucional, ¿es necesario en el Perú?

\section{INTRODUCCIÓN}

El artículo $201^{\circ}$ de la Constitución Política peruana señala que el Tribunal Constitucional es el órgano de control de la Constitución, declaración que ha sido interpretada y ampliada por el artículo $1^{\circ}$ de la Ley Orgánica -Ley $\mathrm{N}^{\circ}$ 28301- de este organismo, el cual establece que el Tribunal Constitucional es el órgano supremo de interpretación y control de la constitucionalidad.

Justamente, una de sus principales atribuciones es la de conocer en instancia única la acción de inconstitucionalidad que se promueva, de conformidad con el inciso $4^{\circ}$ del artículo 200 de la Constitución, contra las normas con rango de ley.

Hasta aquí todo claro, pero cuando pretendemos dar respuesta a la interrogante de ¿cuáles son los criterios que deben de utilizarse para que el citado Tribunal Constitucional desarrolle la determinación de la inconstitucionalidad de las leyes?, se presentan singulares problemas interpretativos. A nivel de la doctrina internacional y de la jurisprudencia francesa, italiana y española principalmente, se ha establecido y determinado cuáles son los criterios o parámetros que utilizan o que deben utilizar los tribunales constitucionales como parámetro para determinar dicha inconstitucionalidad, y para ello se ha elaborado el concepto del bloque de la constitucionalidad, que pretende proponer cuáles son los criterios que deben utilizarse para dar solución a los casos de interpretación y aplicación de la inconstitucionalidad de las leyes.

Pero inmediatamente también, han surgido reacciones por parte de otro sector de la doctrina especializada ${ }^{1}$, quienes cuestionan la utilización de este concepto por innecesario o porque su contenido es impreciso o porque poco puede aportar a la solución de los casos que enfrenta el Constitucional en dicho ámbito; de tal suerte que son válidas las interrogantes: ¿para qué sirve el bloque de constitucionalidad?, ¿es correcta la posición del Tribunal Constitucional de utilizar dicho concepto como parámetro de enjuiciamiento de la constitucionalidad?, ¿es necesaria la traslación de conceptos originados

\footnotetext{
Vid. MEsía, Carlos. «Exégesis del Código Procesal Constitucional», Gaceta Jurídica, Lima, 2004, pp. 829-830; quien señala comentando el artículo $79^{\circ}$ del Código Procesal Constitucional, que esta norma es "entendida en el contexto del discutido concepto del bloque de constitucionalidad, y cita al profesor español RUBIO LLORENTE, Francisco en «La Forma de Poder», Estudios sobre la Constitución, Madrid, Centro de Estudios Constitucionales, p. 100, quien afirma con referencia a España pero aplicable a nuestro ordenamiento que: $n i$ la jurisprudencia del Tribunal Constitucional ni en la obra de los pocos estudiosos que, hasta el presente, han dedicado alguna atención al tema, hay elementos que permitan determinar con exactitud cuál sea el contenido del tal bloque, ni cuál elemento o rasgo que lo constituye como tal, sin que, de otra parte (...) exista definición o referencia normativa alguna del bloque en cuestión.
} 
Artemio Daniel Meza Hurtado - El denominado bloque de constitucionalidad como parámetro de interpretación constitucional, ¿es necesario en el Perú?

en Europa para introducirlos en la actividad interpretativa que desarrolla el Tribunal Constitucional? No existen mayores trabajos destinados a dar respuesta sobre éstas y otras interrogantes acerca de tan importante tema, el cual pretendemos contribuir con su discusión y esclarecimiento.

Un sector de la constitucional ha puesto de relieve que el denominado bloque de constitucionalidad no es más que el resultado de que en el derecho moderno, al constituirse la Constitución Política en "fuente de fuentes", se ha introducido en la ordenación de éstas el criterio de la distribución de materias -obligado por la dinámica de las relaciones sociales traducidas en dicho cuerpo jurídico- dando lugar al fenómeno de las normas interpuestas, que son aquellas normas a las que la Constitución les atribuye la virtualidad de condicionar la creación de otras que sin embargo son de su mismo rango ${ }^{2}$.

\section{ANTECEDENTES}

Los orígenes del denominado "Bloque de Constitucionalidad" se remontan a un suceso acaecido en Francia, cuando el Consejo Constitucional Francés emitió una sentencia de fecha 16 de julio de $1971^{3}$, según la cual para ejercer la actividad de control de las actividades de la administración pública, podía hacer uso de normas y principios generales del derecho, atendiendo a que en el Preámbulo de la Constitución Francesa se hacía referencia a la Constitución derogada de 1946 y a la Declaración de los Derechos del Hombre y del Ciudadano de 1789, por lo que se argumentó que como consecuencia lógica se debían integrar estas normas y principios a la Constitución, adquiriendo "valor constitucional" para ser utilizados en los juicios de constitucionalidad de las normas jurídicas a las que se atribuía vicios de inconstitucionalidad ${ }^{4}$.

Cuando la tesis creada originalmente en Francia es trasladada a la doctrina constitucional española, ésta la adopta pero con matices diferentes y es de allí

2 De Otто, Ignacio, «Derecho Constitucional», p. 94, cit. por Mesía, Carlos en Exégesis del Código Procesal Constitucional, p. 830.

3 Vid. UPRIMNY YEPES, Rodrigo. «Bloque de constitucionalidad, derechos humanos y proceso penal», Bogotá, Consejo Superior de la Judicatura, Escuela Judicial "Rodrigo Bonilla", 2006, p. 38, citado por REYES KURI, Juan Fernando. "La inconstitucionalidad de algunas restricciones al derecho a ser elegido en Colombia", en Revista Derecho del Estado, $N^{\circ} 23$, diciembre, 2009, p. 149, quien recalca que la idea misma del Bloque de Constitucionalidad y los debates que le están asociados son tan antiguos como la propia justicia constitucional. Pero otra cosa es la concreción de la categoría y sus intentos de precisión dogmática, que es mucho más reciente y se origina en la práctica del Consejo Constitucional francés en el marco de la llamada V República.

4 Vid. MANILI, Pablo. «El ejercicio incompleto del poder constituyente y el bloque de constitucionalidad en España», en Revista Española de Derecho Constitucional, Año 9, N²7, Setiembre-Diciembre de 1989, también en: www.pablomanili.com.ar/art_ejercicio.doc, quien pone de relieve que no obstante que este concepto efectivamente tiene su origen en el derecho francés, el mismo ha adquirido relevancia y renombre en Latinoamérica a través del derecho español, no obstante que este es muy diferente al concepto francés. 
Artemio Daniel Meza Hurtado - El denominado bloque de constitucionalidad como parámetro de interpretación constitucional, ¿es necesario en el Perú?

de donde se ha trasladado el concepto, que está siendo desarrollado por el Tribunal Constitucional; por ello es que en el presente trabajo necesariamente tendremos que referirnos al significado del bloque constitucional en estos dos países.

Asimismo el presente trabajo pretende responder a la interrogante respecto a que si es necesario denominar o adoptar doctrinas que fueron creadas y concebidas para otras situaciones jurídicas para establecer el parámetro de constitucionalidad, no bastaría una adecuada interpretación de acuerdo a los "criterios de interpretación constitucional" existentes y que han sido desarrollados profusamente por la doctrina constitucional moderna

La noción del bloque de constitucionalidad, como se aprecia, es de origen doctrinal y no jurisprudencial, puesto que cuando se emitió el fallo de 1971, por el tribunal administrativo francés, los estudiosos empezaron a explicar sus consecuencias a través del principio de constitucionalidad, asimilándolo a la doctrina del bloque de legalidad utilizada por el Derecho Administrativo ${ }^{5}$.

El concepto de bloque de constitucionalidad ha sido tomado del Derecho administrativo, donde se maneja el concepto de bloque de legalidad; sobre el particular, es conveniente precisar que en el Perú el Tribunal Constitucional a través de la acción de inconstitucionalidad, evalúa si una ley o una norma con rango de ley transgrede por la forma o por el fondo, la norma suprema; se trata, en principio, de un juicio abstracto respecto a dos normas de diversa jerarquía. Por un lado, la Constitución que actúa como parámetro en la medida que es la Lex Legum; y, por otro, la ley o las normas con rango de ley, que constituyen las fuentes sometidas a ese control.

La inconstitucionalidad de una ley, prima facie, se genera por la incompatibilidad entre las fuentes legales sometidas a control y la Constitución, y no porque una de ellas colisione, viole o transgreda a otra de su misma jerarquía. Y es que no se presenta un problema de validez constitucional cada vez que se produce la colisión de dos normas del mismo rango, sino un típico problema de antinomia, resoluble conforme a las técnicas que existen en nuestro ordenamiento jurídico (v.g. "ley especial deroga ley general", "ley posterior deroga ley anterior", etc.).

\footnotetext{
5 Vid. CARPIO MARCOS, Edgar, en «Bloque de Constitucionalidad y Proceso de inconstitucionalidad de las leyes» p. 83, en www.iidpc.org/revistas/4pdf/93_128.pdf, (consulta: 30 de junio del 2010), quien refiere que este concepto de "bloque de constitucionalidad es tributario de una idea análoga existente en el proceso contencioso administrativo francés, era una adaptación del concepto "bloque de legalidad", creado por el maestro de Derecho administrativo francés Maurice Hariou, a principios del siglo XX, que era utilizado por el Consejo de Estado francés para efectuar el control de legalidad de los actos administrativos.
} 
Artemio Daniel Meza Hurtado - El denominado bloque de constitucionalidad como parámetro de interpretación constitucional, ¿es necesario en el Perú?

La posición del tribunal que será desarrollada, afirma expresamente no solo la aceptación de esta tesis del bloque de constitucionalidad sino que en diversas resoluciones ha delineado cuáles son las normas que integran el denominado "parámetro de constitucionalidad".

\section{DEFINICIÓN}

El bloque de constitucionalidad es un concepto que alude a las fuentes formalmente no constitucionales que integran el parámetro a utilizar en una acción de inconstitucionalidad ${ }^{6}$. Así en diversas sentencias el Tribunal Constitucional nacional se ha pronunciado estableciendo que se debe comprender como integrante del bloque de constitucionalidad a toda norma de naturaleza jurídica, que si bien ni está desarrollada por la Constitución, tiene algún tipo de jerarquía constitucional y sirva como parámetro constitucional para la toma de decisión tanto del Tribunal Constitucional como de los demás órganos jurisdiccionales ${ }^{7}$.

Como se sabe la Constitución en principio debería ser el único parámetro para determinar dicha constitucionalidad, pero en algunas ocasiones el parámetro que utilice el Tribunal Constitucional para resolver una acción de inconstitucionalidad puede estar comprendido en fuentes distintas de la Constitución ${ }^{8}$.

El Tribunal Constitucional peruano ha reconocido que en nuestro ordenamiento jurídico, la referencia al parámetro de constitucionalidad o bloque de la constitucionalidad, tiene como antecedente inmediato el artículo $22^{\circ}$ de la

\footnotetext{
6 En el mismo sentido Olano García, Hernán Alejandro. «El Bloque de Constitucionalidad en Colombia». Estudios Constitucionales. Año/Vol 3, No 001, pp. 231-242. Afirma que por Bloque de Constitucionalidad se puede entender un conjunto normativo que contiene disposiciones, principios o valores materialmente constitucionales, que se encuentran fuera de la Constitución fundamental.

7 Vid. al respecto la STC en los procesos acumulados 0020-2005-PI/TC y 0021-2005-PI/TC en la demanda de inconstitucionalidad interpuesta por el Presidente de la República contra la Ordenanza Regional N. ${ }^{\circ} 031$ 2005-GRC/CRC, y las Ordenanzas Regionales N. ${ }^{\text {s }}$ 015-2004-CR-GRH y 027-2005-E-CR-GRH, del Gobierno Regional de Huánuco, donde se precisa que cuando se trate de efectuar una interpretación recurriendo al bloque de constitucionalidad de las normas de los Gobiernos Regionales, no significa" que allí se agoten las normas que pueden conformar dicho bloque, la apertura de éste a otras normas, ya sean leyes orgánicas o simples leyes estatales o decretos legislativos, depende del tipo de materias que hayan sido reguladas por una ordenanza regional y particularmente, de la clase de competencia de que se trate.

8 Vid. STC 0007-2002-AI, del 27 de agosto del 2003, Fund. 5, donde se reconoce esta posibilidad, siempre que esa condición sea reclamada directamente por una disposición constitucional (v.g. la ley autoritativa en relación con el decreto legislativo). En tales casos, estas fuentes asumen la condición de "normas sobre la producción jurídica", en un doble sentido; por un lado, como "normas sobre la forma de la producción jurídica", esto es, cuando se les encarga la capacidad de condicionar el procedimiento de elaboración de otras fuentes que tienen su mismo rango; y, por otro, como "normas sobre el contenido de la normación", es decir, cuando por encargo de la Constitución pueden limitar su contenido.
} 
Artemio Daniel Meza Hurtado - El denominado bloque de constitucionalidad como parámetro de interpretación constitucional, ¿es necesario en el Perú?

Ley Orgánica del Tribunal Constitucional, hoy incorporada en el texto del artículo del $79^{\circ}$ del Código Procesal Constitucional con rango de "principio de interpretación", según el cual para apreciar la validez constitucional de las normas el Tribunal Constitucional considerará, además de las normas constitucionales, las leyes que dentro del marco constitucional, se hayan dictado para determinar la competencia o las atribuciones de los órganos del Estado o el ejercicio de los derechos fundamentales de la persona.

De esta forma, afirmarse que el bloque de constitucionalidad está compuesto por aquellas normas y principios que, sin aparecer formalmente en el articulado del texto constitucional, son utilizados como parámetros del control de constitucionalidad de las leyes, por cuanto han sido normativamente integrados a la Constitución. Se afirma que éstos son "verdaderos principios y reglas de valor constitucional", esto es, son normas situadas en el nivel constitucional, a pesar de que puedan a veces contener mecanismos de reforma diversos al de las normas del articulado constitucional stricto sensu ${ }^{9}$.

En nuestro país el Tribunal Constitucional identifica como sinónimos los conceptos de "parámetro de control constitucional o "bloque de la Constitucionalidad", cuyo contenido lo integran "otras fuentes distintas de la Constitución, en concreto, determinadas fuentes con rango de ley, denominándolas normas sobre la producción jurídica en su vertiente formal es decir sobre la forma de producción jurídica, el procedimiento de elaboración de otras fuentes del mismo rango y también se refiere a las normas sobre el contenido de la regulación, las cuales por encargo del texto constitucional pueden limitar su contenido ${ }^{10} 11$.

\section{TIPOS O CLASES DEL BLOQUE DE CONSTITUCIONALIDAD}

La doctrina ha identificado dos sentidos que se le podría dar al concepto del bloque de constitucionalidad:

\footnotetext{
9 Vid. Sentencia $\mathrm{N}^{\circ} \mathrm{C}-\mathbf{2 2 5 / 9 5}$ de la Corte Constitucional de Colombia, citada por RuEDA AGUILAR, Dolores, en «El Bloque de constitucionalidad en el sistema colombiano», p. 6, accesible en : https://www.scjn. gob.mx/Transparencia/Lists/Becarios/Attachments/88/Becarios_088.pdf, quien además sostiene que la noción de prevalencia de los tratados sobre derechos humanos y de derecho internacional humanitario permite concluir que éstos forman con el resto del texto constitucional un "bloque de constitucionalidad" cuyo respeto se impone a la ley.

10 Vid. STC. 007-2002-AI/TC; STC Nº041-2004-AI/TC.

11 Mesía, Carlos, Exégesis del Código..., cit. p. 830, de igual forma señala que aún cuando la doctrina y la jurisprudencia es errática, se puede definir el bloque de constitucionalidad, como el conjunto de normas que no están incluídas en la Constitución, algunas de las cuales delimitan competencias, pero cuya infracción determina la inconstitucionalidad de la ley sometida a examen. Visto así, algún grado de parentesco existiría entre el llamado "bloque de constitucionalidad y las denominadas "normas interpuestas".
} 
Artemio Daniel Meza Hurtado - El denominado bloque de constitucionalidad como parámetro de interpretación constitucional, ¿es necesario en el Perú?

\subsection{Bloque de constitucionalidad stricto sensu}

Que se encontraría confirmado por aquellos principios y normas de valor constitucional, referidas al texto de la Constitución propiamente dicha y a los tratados internacionales que consagren derechos humanos cuya limitación se encuentre prohibida durante los estados de excepción.

ARANGO OLAYA por su parte considera que dentro de esta clasificación se encuentran comprendidos:

a. El preámbulo de la Constitución;

b. La Constitución;

c. Los Tratados Limítrofes de derecho internacional ratificados por el Estado;

d. La ley estatutaria que regula los estados de excepción;

e. Los Tratados de Derecho Internacional Humanitario;

f. Los Tratados de Derecho Internacional que reconocen derechos intangibles;

g. Los artículos de los Tratados de Derecho Internacional de Derechos Humanos ratificados por Colombia, cuando se trate de derechos reconocidos por la Carta y,

h. La doctrina elaborada por los tratados internacionales u órganos de control de los tratados de derechos humanos en relación con esas normas internacionales restrictivamente y sólo en determinados casos.

\subsection{Sentido lato sensu del bloque de constitucionalidad}

Alude a que dicho bloque estaría compuesto por todas aquellas normas de diversa jerarquía, que sirven como parámetro para efectuar el control de la constitucionalidad de la legislación; RUEDA AGUILAR considera que conforme a este sentido, el bloque de constitucionalidad estaría conformado no sólo por el articulado correspondiente de la Constitución sino además por los tratados internacionales de derechos humanos, por las denominadas leyes orgánicas y además -en algunas ocasiones- por las leyes estatutarias ${ }^{12}$.

La doctora Mónica ARANGO Olaya sostiene al respecto que el bloque de constitucionalidad en sentido lato como parámetro de constitucionalidad de

12 Vid. Rueda Aguilar, Op. cit, pp.12-13, quien consigna el texto del artículo 152 de la Constitución de Colombia regula las denominadas leyes estatutarias de la siguiente manera: " Art. 152.- Mediante las leyes estatutarias, el Congreso de la República regulará las siguientes materias : a. Derechos y deberes fundamentales de las personas y los procedimientos y recursos para su protección; b. Administración de justicia; c. Organización y régimen de los partidos y movimientos políticos; estatuto de la oposición y funciones electorales; d. Instituciones y mecanismos de participación ciudadana; Estados de Excepción. 
Artemio Daniel Meza Hurtado - El denominado bloque de constitucionalidad como parámetro de interpretación constitucional, ¿es necesario en el Perú?

las leyes está compuesto por: a. Las leyes orgánicas, y b. Las leyes estatuarias en lo pertinente ${ }^{13}$.

\section{EL CASO DE FRANCIA}

En el año 1975, Louis FAVOREAU en un trabajo dedicado a explicar una decisión del Consejo Constitucional Francés (la Decisión D-44 del 16 de julio de 1971) que declaró inconstitucional una ley que limitaba el régimen de las asociaciones, utiliza la expresión "Bloque de constitucionalidad" para explicar como el Consejo consideró que para analizar la invalidez de dicha norma no sólo debía considerar a la Constitución francesa de 1958, sino que también utilizó como parámetro de constitucionalidad a la Declaración Francesa de los Derechos del Hombre y del Ciudadano de 1789, explicando el Consejo que ello era posible en razón que si bien dicho documento era distinto a la Constitución formalmente, ésta en su preámbulo aludía a dicha declaración como principio interpretativo.

La expresión al parecer se tomó del uso que se efectuaba en el Derecho administrativo de una similar: "bloque de legalidad", que servía para efectuar el control de legalidad de los actos administrativos y que hacían referencia a todas las reglas que se imponen en la administración.

El concepto de bloque de constitucionalidad alude en consecuencia a un conjunto de normas y principios de valor formalmente constitucional.

Por otro lado, en lo que atañe a la función procesal que desempeña el concepto en este país, todas las normas que lo componen sirven como normas de referencia o parámetro de control sobre la totalidad de fuentes que en el derecho francés pueden someterse a la evaluación del Consejo, y es que en Francia como explica CARPIO MARCOS ${ }^{14}$, la noción del bloque de constitucionalidad está fundamentalmente vinculada a la unidad de rango de las fuentes que la componen, siendo la función procesal que cumplen una consecuencia de ello.

\footnotetext{
13 Vid. Arango Olaya, Mónica. «El bloque de constitucionalidad en la jurisprudencia de la Corte Constitucional colombiana», p. 102, disponible en: http://www.icesi.edu.co/contenido/pdfs/C1C-marango-bloque.pdf

14 CARPIO MARCOS, Edgar, en «Bloque de Constitucionalidad y Proceso de inconstitucionalidad de las leyes» p. 89, en www.iidpc.org/revistas/4pdf/93_128.pdf
} 
Artemio Daniel Meza Hurtado - El denominado bloque de constitucionalidad como parámetro de interpretación constitucional, ¿es necesario en el Perú?

\section{EL BLOQUE DE CONSTITUCIONALIDAD EN ESPAÑA}

En este país, a diferencia del caso francés, esta tesis tuvo su origen en la jurisprudencia desarrollada por el Tribunal Constitucional Español desde la expedición de la Sentencia del Tribunal Constitucional No $10 / 82^{15}$, pero con la diferencia que este desarrollo responde a la solución de diversos problemas. Es más como afirma REQUEJO RODRÍGUEZ ${ }^{16}$, existe tal diversidad su contenido y alcance que se ha llegado a afirmar que esta institución fue "raptada del constitucionalismo francés"17.

La posición del tribunal español ha sido variada, incluyéndose en este concepto a los "Estatutos de Autonomía" y posteriormente incluye el Reglamento Parlamentario (en forma similar el Tribunal Constitucional peruano ha dado a entender que el reglamento del Congreso también integraría el bloque de constitucionalidad: cualquier parecido es solo una coincidencia), no existiendo en consecuencia en España una sola versión sino "versiones del bloque de constitucionalidad".

La doctrina española, según Antonio DE CABO DE LA VEGA, ha identificado cuatro significados del concepto:

1. En primer lugar, el que se refiere (como equivalente a lo que en la doctrina italiana se denomina "normas interpuestas", esto es,) a aquellas normas que no siendo formalmente constitucionales, sin embargo, sirven de parámetro para determinar la validez de otras fuentes. Incluidos en esta concepción del bloque, estarían las normas de delegación de facultades legislativas, los reglamentos de las cámaras, los estatutos de autonomía y ciertos tratados sobre derechos humanos.

2. La de la comprensión del bloque según el cual se trataría de un conjunto concreto de normas que sirve para enjuiciar la constitucionalidad de otra norma específica, el bloque sólo surgiría en el supuesto de su

15 Vid. CARPIO MARCOS, Edgar. «Bloque de constitucionalidad y proceso de inconstitucionalidad de las leyes», Conferencia pronunciada en la Facultad de Derecho y Ciencias Políticas de la Universidad Nacional San Cristóbal de Huamanga, disponible en: www.iidpc.org/revistas/4/pdf/93_128.pdf

16 Requejo Rodríguez, Paloma. «Bloque de constitucional y comunidades autónomas», en Revista de la facultad de Derecho de la Universidad Complutense, pp. 117-118, cit. por CARPIO MARCOS, op. cit. p. 90.

17 Vid. García Belaúnde, Domingo, "Estado y Municipio en el Perú", en http://www.garciabelaunde.com/ articulos/EstadoyMunicipio.pdf, quien el mismo afirma: La doctrina del bloque de la constitucionalidad, o más brevemente, del bloque de constitucionalidad (bloc de constitutionnalité) es de origen francés; nació en y para los franceses, con buenos resultados. Al ser trasladada a España, para sorpresa de sus vecinos, ha creado una realidad distinta, multiforme y confusa. Últimamente ha pretendido ser también aplicada al Perú, con resultados similares. 
Artemio Daniel Meza Hurtado - El denominado bloque de constitucionalidad como parámetro de interpretación constitucional, ¿es necesario en el Perú?

impugnación. Se habla así de la determinación de 'su bloque' (de la norma impugnada), y no de un bloque en general.

3. También con la expresión el bloque de constitucionalidad se aludiría a aquellas normas "materialmente" constitucionales que, por supuesto, no se encuentran recogidas en la Constitución formal o escrita, una crítica frontal a tal pretensión (la de equiparar la noción del bloque como un conjunto de normas materialmente constitucionales). En términos jurídicos y en un ordenamiento organizado en función de formas, no hay más Constitución que la que formalmente tiene tal carácter; no hay norma al margen de la forma ni normas revestidas de una forma específica que, en virtud de funciones 'materiales', puedan recabar para sí las cualidades propias de normas albergadas en formas distintas. Admitir la existencia de normas que, sin serlo formalmente, son materialmente constitucionales, por tener como objeto la producción de normas por los órganos superiores del Estado, supone partir del presupuesto de que, en primer lugar, lo definitivo de las constituciones es precisamente tal objeto y de que, en segundo término, el que positivamente no se formalicen como constitucionales normas que inequívocamente lo son desde el punto de vista lógico no tiene mayor trascendencia que la dificultad que con ello se genera a la hora de identificar las verdaderas normas constitucionales de un ordenamiento".

4. El que alude a la existencia de un ordenamiento complejo, en el que las normas que la componen tendrían por propósito regular el reparto de competencias entre el Estado y las comunidades autónomas. Desde este punto de vista, el bloque cumpliría una doble función: Por un lado, para comprender al conjunto de normas materialmente constitucionales, en el sentido que ellas regulan, ex constitutione, la distribución de competencias entre el gobierno central y el regional; y, de otro, como normas que cumplen una función procesal, en tanto que constituyen el parámetro de aquella legislación que incida en la regulación de aquella distribución de competencias $^{18}$.

En razón de esta doble función y de su relación con los anteriores conceptos del bloque, es que DE CABO ha podido advertir que esta última versión "no aparece incontaminada, sino simultáneamente con las demás", deudora

18 DE CABO DE LA VegA, Antonio. «Nota sobe el bloque de constitucionalidad», en Jueces para la democracia, $\mathrm{N}^{\circ} 24$, Noviembre 1995. 
Artemio Daniel Meza Hurtado - El denominado bloque de constitucionalidad como parámetro de interpretación constitucional, ¿es necesario en el Perú?

de las concepciones anteriores y, por tanto, susceptible de destinarle las mismas críticas argumentales.

En definitiva en España, tras el concepto del bloque de constitucionalidad se ha pretendido explicar diversos fenómenos, no de un modo totalmente satisfactorio, que ha llevado a Francisco RUBIO LLORENTE a expresar que el artículo 28 de la LOTC español ${ }^{19}$, a partir del cual se ha construido la idea del bloque, no es otra cosa que una disposición "superflua", "que no puede servir... de base para construir un concepto de bloque de la constitucionalidad compatible con nuestro derecho positivo, por una doble razón:

- En primer lugar, y sobre todo, porque la utilización como medida de la constitucionalidad de otras leyes, de las normas a que dicho precepto alude no es ni puede ser consecuencia de esa alusión ni depende, por tanto, de ella.

- En segundo término, porque el régimen jurídico de las normas aludidas es muy heterogéneo: ni la transgresión de todas ellas determina el mismo vicio, ni la función constitucional de la mayor parte de esas normas se agota, a diferencia de lo que ocurre (cuando ocurre) con la ley orgánica, en los procedimientos de declaración de inconstitucionalidad", por lo que a su juicio, si se conserva, debería de reservarse "para designar aquellas normas que tienen como contenido propio, no como efecto derivado, la delimitación de competencias entre el Estado y las comunidades autónomas".

5. En el derecho español, explica MANILI, la doctrina y la jurisprudencia españolas toman la expresión "bloque de constitucionalidad" del derecho francés porque este concepto les era útil como común denominador para referirse a las normas que están dentro y fuera de la constitución pero que sirven por igual para el reparto competencial entre el estado central y las comunidades Autónomas que existen en este país y donde dichas

19 Artículo 28 de la Ley Orgánica del Tribunal Constitucional español.

Uno. Para apreciar la conformidad o disconformidad con la Constitución de una Ley, disposición o acto con fuerza de Ley del Estado o de las Comunidades Autónomas, el Tribunal considerará, además de los preceptos constitucionales, las Leyes que, dentro del marco constitucional, se hubieran dictado para delimitar las competencias del Estado y las diferentes Comunidades Autónomas o para regular o armonizar el ejercicio de las competencias de estas.

Dos. Asimismo el Tribunal podrá declarar inconstitucionales por infracción del artículo 81 de la Constitución los preceptos de un Decreto-ley, Decreto Legislativo, Ley que no haya sido aprobada con el carácter de Orgánica o Norma Legislativa de una Comunidad Autónoma en el caso de que dichas disposiciones hubieran regulado materias reservadas a Ley Orgánica o impliquen modificación o derogación de una Ley aprobada con tal carácter cualquiera que sea su contenido. 
Artemio Daniel Meza Hurtado - El denominado bloque de constitucionalidad como parámetro de interpretación constitucional, ¿es necesario en el Perú?

comunidades participan del dictado directo de la constitución nacional por la vía de limitar los poderes centrales al delimitar sus propias competencias $^{20}$.

6. Por lo expuesto, no está determinado con exactitud cuál es el contenido del bloque, ya que la lista de normas que lo integran no parece estar cerrada, diferenciándose de otros países como Colombia, Argentina y Panamá, en el sentido que nada hay en este concepto referido a los derechos humanos, sino más bien refiriéndose como se ha señalado, el bloque de constitucionalidad sólo al reparto de competencias entre estado central y las comunidades autónomas.

\section{EL BLOQUE DE CONSTITUCIONALIDAD EN LATINOAMÉRICA}

A continuación detallamos la aplicación de la institución en algunos países de nuestro continente.

\subsection{El bloque de constitucionalidad en Colombia}

En Colombia, el concepto de bloque de constitucionalidad ha sido desarrollado ampliamente por la jurisprudencia constitucional colombiana y como lo pone de relieve RUEDA AGUILAR, lo que permite resolver una controversia judicial tomando en cuenta no sólo los artículos de la Constitución sino otras disposiciones y principios de valor constitucional no contenidos en ésta ${ }^{21}$, siendo en este país donde se desarrolla principalmente este concepto.

Como reseña REYES KURI, cuando se dicta la Sentencia C-225 de 1995, es cuando se trata por primera vez el concepto de bloque de constitucionalidad definiéndolo como "aquellas normas y principios que, sin aparecer formalmente en el articulado del texto constitucional, son utilizados como parámetros del control de constitucionalidad de las leyes, por cuanto han sido normativamente integrados a la Constitución, por diversas vías y por mandato de la propia Constitución"22.

\footnotetext{
20 Vid. MANILI, Pablo. «El ejercicio incompleto del poder constituyente y el bloque de constitucionalidad en España», en Revista Española de Derecho Constitucional, Año 9, N 27, Setiembre - Diciembre de 1989; también en: www.pablomanili.com.ar/art_ejercicio.doc

${ }^{21}$ RuEDA AGUILAR, Dolores. «El bloque de constitucionalidad en el sistema colombiano», disponible en: https://www.scjn.gob.mx/Transparencia/Lists/Becarios/Attachments/88/Becarios_088.pdf

22 REYES KURI, "la inconstitucionalidad..." cit. p. 150.
} 
Artemio Daniel Meza Hurtado - El denominado bloque de constitucionalidad como parámetro de interpretación constitucional, ¿es necesario en el Perú?

7.1.2. Posteriormente la Corte Constitucional colombiana amplía este sentido del término bloque de constitucionalidad, apreciándose en consecuencia dos interpretaciones: (i) la primera de ellas donde se hace alusión al cuerpo de normas que, con igual jerarquía, complementan las normas constitucionales y que son producto del vigor dinámico de dicha Constitución y cuyo contenido atiende a los avances de la comunidad internacional en el tema de los derechos humanos; y (ii) también se entiende por bloque de constitucionalidad al conjunto de normas, de naturaleza no siempre constitucional, que sirve al tribunal para realizar el control de constitucional de la ley.

7.1.3. Asimismo debe de ponerse de relieve que es la propia Corte Constitucional que en las sentencias C-774- de 2001, C-802 de 2002, T-786 de 2003 y C-028 de 2006, ha reconocido explícitamente que la Convención Americana sobre Derechos Humanos hace parte del bloque de constitucionalidad ${ }^{23}$.

7.1.4. A partir de los inicios de la década de los años noventa del siglo pasado en Colombia se consolida, como señala UPRIMNY YEPES ${ }^{24}$, la idea de que la Constitución no es un texto que se agota con el contenido de sus artículos, sino que formando un "bloque de constitucionalidad" con otras normas, principios e ideologías, contribuye a la adaptación de sus propias disposiciones a las realidades sociales y políticas del país en consonancia con el mundo globalizado, convirtiéndose en un derecho en constante evolución y que se halla en armonía con las transformaciones sociales; de esta forma la Corte Constitucional ha interpretado el art. 93 de la Constitución -por ejemplo- en el sentido que los tratados ratificados por Colombia sobre derechos humanos, que prohíben su limitación en los estados de excepción, tienen la virtud de poder incluir nuevos derechos no consagrados en el texto constitucional ${ }^{25}$.

${ }^{23}$ Vid. REYES KURI, op. cit. p. 153, quien refiere que al respecto no cabe duda de que dicho tratado es parte del bloque de constitucionalidad en Colombia, cuyo respeto y seguimiento estricto deben seguir, no sólo el productor del derecho positivo, sino también el ejecutor de la norma y su intérprete autorizado, ya que en dicha sumisión reside la validez jurídica de sus actuaciones.

24 Vid. UPRIMNY YEPES, Rodrigo. «Bloque de constitucionalidad, derechos humanos y proceso penal», Bogotá, Consejo Superior de la Judicatura, Escuela Judicial "Rodrigo Bonilla", 2006, pp. 31-32.

25 Finalmente queremos poner de relieve que como lo señala la Licenciada RUEDA AGUILAR, "la conformación del bloque de constitucionalidad en Colombia es muy compleja debido a que es necesario que exista una regla constitucional clara que ordene la inclusión de las normas al bloque, lo que es muy difícil dadas las diversas técnicas de reenvío admitidas por la Constitución colombiana para establecer un orden sistemático, op. cit. p. 13. 
Artemio Daniel Meza Hurtado - El denominado bloque de constitucionalidad como parámetro de interpretación constitucional, ¿es necesario en el Perú?

\subsection{El bloque de constitucionalidad en Ecuador}

Mediante el fallo del Tribunal Constitucional contenido en la Resolución No. 001-2004-DI, Sentencia del pleno del tribunal del 9 de julio del 2004, se esboza en el ordenamiento jurídico ecuatoriano el complicado tema del bloque de de constitucionalidad.

7.2.1. El caso se trata de la destitución de un Juez ecuatoriano por haber efectuado declaraciones en un medio televisivo sobre aspectos jurídicos de una detención, este interpone una acción de amparo constitucional por considerar que se atentaba contra su derecho a la libertad a la libertad de expresión que se encuentra consagrada en al artículo 23.9 de la Constitución y solicita a su vez que se declare inaplicable el inciso 2 del art. 255 del Código de Procedimiento Penal que señalaba: “En ningún caso, el juez, o magistrado que conozca de una causa penal sometida a su resolución puede formular declaraciones públicas o privadas a los medios de comunicación social, ni antes ni después del fallo. La violación de esta prohibición será sancionada con su destitución, sin perjuicio de las responsabilidades civiles y penales que hubieren".

7.2.2. El Tribunal Constitucional declaró inconstitucional parte del art. 255, no por entrar en contradicción contra el texto literal del art. 23.9 de la Constitución ecuatoriana, sino fundamentalmente por oponerse al art. 23.9, pero interpretado a la luz de los pactos internacionales de derechos humanos y de algunas disposiciones de la legislación nacional -que no eran normas constitucionales-, por lo como observa con agudeza RIOFRíO MARTínEZVILLALBA, significa que el Tribunal ha terminado constitucionalizando las normas internacionales y las legislativas correspondientes ${ }^{26}$.

7.2.3. De esta forma el bloque de constitucionalidad ecuatoriano está conformado por (i) la Constitución política; (ii) los tratados internacionales, que se insertan dentro de la normativa con máxima jerarquía; (iii) ciertas Leyes Orgánicas que desarrollan el texto constitucional, lo que eleva el status de los tratados de derechos humanos y les concede el de constitucional, así como algunas normas jurídicas de derecho interno, a la vez abre nuevas perspectivas para el campo de las autonomías, de la descentralización, de las competencias de las diferentes instituciones del Estado incluyendo las propias del Tribunal Constitucional ${ }^{27}$.

\footnotetext{
26 Vid. Riofrío Martínez Villalba, Juan Carlos. «El bloque de constitucionalidad pergeñado por el Tribunal Constitucional», en FORO, Revista de derecho, No. 6, UASB-Ecuador/CEN, Quito 2006, p. 229.

27 Riofrío Martínez Villalba, ibídem. p.235.
} 
Artemio Daniel Meza Hurtado - El denominado bloque de constitucionalidad como parámetro de interpretación constitucional, ¿es necesario en el Perú?

\section{EL PARÁMETRO DE CONSTITUCIONALIDAD EN EL PERÚ}

El artículo $22^{\circ}$ de la anterior Ley Orgánica del Tribunal Constitucional ${ }^{28} \mathrm{~N}^{\circ}$ 26435, hacía referencia expresa al bloque de constitucionalidad. La nueva Ley Orgánica del Tribunal Constitucional No 28301 no hace referencia al citado bloque, regulando sin embargo de similar forma en el Código Procesal Constitucional aprobado por Ley $\mathrm{N}^{\mathrm{o}} 28237$ y vigente desde el uno de diciembre del año dos mil cuatro, su contenido material en el Art. $79^{\circ}$ con el siguiente texto: "Para apreciar la validez constitucional de las normas el Tribunal Constitucional considerará, además de las normas constitucionales, las leyes que, dentro del marco constitucional, se hayan dictado para determinar la competencia o las atribuciones de los órganos del Estado o el ejercicio de los derechos fundamentales de la persona"; definiendo de esta forma, en mi concepto, el "parámetro para evaluar la validez constitucional de las normas en un proceso de inconstitucionalidad".

Sin embargo, existen problemas de carácter interpretativo para determinar el alcance y significado de "leyes dictadas dentro del marco constitucional", así como de la expresión "leyes dictadas para determinar la competencia o atribuciones de los órganos del Estado" y de "leyes para determinar el ejercicio de los derechos fundamentales de la persona", teniendo para ello que acudir a la Jurisprudencia del propio Tribunal Constitucional, así como a la doctrina que estableció este concepto.

\subsection{La posición del Tribunal Constitucional peruano}

8.1.1. En primer lugar debe señalarse que el Tribunal Constitucional ha reconocido expresamente la denominación del denominado bloque de constitucionalidad como parámetro interpretativo, así en el STC Exp. $\mathbf{N} .^{\circ}$ 00007-2002-AI/TC, LIMA, caso Municipalidad Metropolitana de Lima, en el Fundamento tercero, puede apreciarse que el Constitucional ha señalado que el parámetro para evaluar si una ley o una norma con rango de ley, transgrede por la forma o por el fondo la Norma Suprema, es la Constitución, la que actúa como parámetro, en la medida que es la Lex Legum (sic).

\footnotetext{
28 Así la Ley Orgánica del Tribunal Constitucional establecida por Ley 26435 del mes de enero del año 1995 establecía en su artículo 220 "Bloque de constitucionalidad. Para apreciar la constitucionalidad o la inconstitucionalidad de las normas mencionadas en el artículo $20^{\circ}$ (referidas a que normas podrían ser impugnadas como inconstitucionales), el tribunal considera, además de los preceptos constitucionales las leyes que dentro del marco constitucional, se hayan dictado para determinar la competencia o las atribuciones de los órganos del Estado" dichas normas eran Las leyes, Decretos Legislativos, Decretos de urgencia, tratados internacionales, reglamentos del Congreso, normas regionales de carácter general (Ordenanzas Regionales) y Ordenanzas Municipales.
} 
Artemio Daniel Meza Hurtado - El denominado bloque de constitucionalidad como parámetro de interpretación constitucional, ¿es necesario en el Perú?

8.1.2. Pero también ha señalado el tribunal que, en determinadas ocasiones, ese parámetro puede comprender a "otras fuentes distintas de la Constitución", en concreto, a determinadas fuentes con rango de ley, siempre que esa condición sea reclamada directamente por una disposición constitucional (v.g. la ley autoritativa en relación con el decreto legislativo). En tales casos, estas fuentes asumen la condición de "normas sobre la producción jurídica", en un doble sentido; por un lado, como normas sobre la forma de la producción jurídica, esto es, cuando se les encarga la capacidad de condicionar el procedimiento de elaboración de otras fuentes que tienen su mismo rango; y, por otro, como normas sobre el contenido de la normación, es decir, cuando por encargo de la Constitución pueden limitar su contenido".

8.1.3. Como corolario de lo expuesto, concluye el tribunal: "Tal capacidad (de fuentes formalmente no constitucionales para integrar el parámetro), es lo que en el derecho constitucional comparado se ha abordado bajo la denominación de "bloque de constitucionalidad" (así, en España) o de "normas interpuestas" (caso de Italia)".

8.1.4. En la demanda interpuesta por la Defensoría del Pueblo contra las Ordenanzas que regularon el régimen de arbitrios de la Municipalidad de Miraflores en el periodo 1997 a 2004, el tribunal señala que:

"el contenido del parámetro de constitucionalidad puede comprender a otras fuentes distintas de la Constitución y en concreto, a determinadas fuentes con rango de ley, siempre que esa condición sea reclamada directamente por una disposición constitucional, como por ejemplo la ley autoritativa en relación con un Decreto Legislativo, nuevamente -como se señaló en la introducción de este trabajo-, el Constitucional identifica como sinónimos a los términos "parámetro de constitucionalidad" con el "bloque de constitucionalidad" (vid. Fund. II, Punto B) y en este caso considera que integran dicho bloque tanto la Ley Orgánica de Municipalidades como la Ley de Tributación Municipal ${ }^{29}$.

8.1.5. En el caso de la demanda de Inconstitucionalidad interpuesta por el alcalde de la Municipalidad de Lima contra la Ordenanza N 181-MSS de la Municipalidad de Surco, el Tribunal Constitucional nuevamente, reconoce que cuando se constate la existencia de un "conflicto de competencias o atribuciones", también resulta necesario que ellas gocen de reconocimiento constitucional, para lo cual debe tomarse en cuenta el bloque de constitucionalidad y señala que:

\footnotetext{
${ }_{29}$ Vid. STC en el Exp. № 053-2004-PI/TC, LIMA-DEFENSORÍA DEL PUEBLO.
} 
Artemio Daniel Meza Hurtado - El denominado bloque de constitucionalidad como parámetro de interpretación constitucional, ¿es necesario en el Perú?

"las normas del bloque de constitucionalidad son aquellas que se caracterizan por desarrollar y complementar los preceptos constitucionales relativos a los fines, estructura, organización y funcionamiento de los órganos y organismos constitucionales, amén de precisar detalladamente las competencias y deberes funcionales de los titulares de éstos, así como los derechos, deberes, cargas públicas y garantías básicas de los ciudadanos",

Reconociendo, así, que la Ley Orgánica de Municipalidades forma parte del bloque de constitucionalidad nacional ${ }^{30}$.

Para finalizar, debe precisarse que "las fuentes que formalmente no son constitucionales, es lo que se ha denominado bloque de constitucionalidad", con lo que nuevamente se vuelve al inicio del problema interpretativo, porque justamente de lo que se trata es de determinar cuáles son las fuentes formales que merecen tal denominación.

8.1.6. En la acción de incumplimiento interpuesta por el Sindicato Único de Expendedores Minoristas de los Mercados Central, San Sebastián y Mercadillo, contra la Sentencia de la Sala Civil de la Corte Superior de Justicia de Cajamarca, el Constitucional en su Fundamento $4^{\circ}$ expresa que la Ley Orgánica de Municipalidades que regula la autonomía política, administrativa y económica de los gobiernos locales en lo que respecta a asuntos de su competencia, determina que tanto dicha Ley orgánica como una ordenanza "tienen rango de ley" y entre ellas no puede aplicarse el principio de jerarquía, por lo que es en virtud del principio de competencia que deben de articularse sus relaciones y reconoce que dicha Ley Orgánica de Municipalidades conforma el "bloque de constitucionalidad".

8.1.7. En el caso del recurso extraordinario interpuesto por Juan MONROY GÁlveZ contra la sentencia de la Primera Sala Civil de la Corte Superior de Justicia de Lima, ante la interpretación de la procedencia de una acción de amparo, en su fundamento octavo, el Tribunal Constitucional señala que:

"la interpretación que efectúa, no sólo abarca las normas constitucionales propiamente dichas, sino que se extiende a todas las demás comprendidas en el denominado "bloque de constitucionalidad".

30 Vid. STC en el Exp. № 0046-2004-PI/TC-LIMA- Alcalde de la Municipalidad de Lima, Fundamentos $3^{\circ}$ al $7^{\circ}$. 
Artemio Daniel Meza Hurtado - El denominado bloque de constitucionalidad como parámetro de interpretación constitucional, ¿es necesario en el Perú?

Añade, que dicho concepto permite completar el marco normativo de un texto fundamental "de por sí sutil o inacabado" (sic). Por ende, afirma el tribunal, dicho bloque, comprende el conjunto de normas constitucionales y las respectivas normas infraconstitucionales que contienen su regulación complementaria ${ }^{31}$.

8.1.8. En el caso de la acción de inconstitucionalidad interpuesta por la Defensoría del Pueblo contra las Ordenanzas N171-MSS y 172-MSS expedidas por la Municipalidad de Santiago de Surco que aprueban el régimen legal tributario y los importes de arbitrios municipales correspondientes al ejercicio fiscal 2004; las Ordenanzas Nos. 003-96-O-MSS, 006-97-O-MSS, 002-98-O-MSS y 01-O-MSS, el artículo $4^{\circ}$ de la Ordenanza $N^{\circ}$ 024-MSS(2000), el artículo $4^{\circ}$ de la Ordenanza $N^{\circ}$ 55-MSS (2001), el artículo $6^{\circ}$ de la Ordenanza $N^{\circ} 92-$ MSS (2002), los artículos $7^{\circ}$ ( y la Segunda Disposición Final de la Ordenanza $\mathrm{N}^{\circ}$ 128-MSS (2003), así como el artículo $5^{\circ}$ de la Ordenanza $\mathrm{N}^{\circ} 130-\mathrm{MSS}$ (2003), por contener vicios de inconstitucionalidad, el Tribunal señala que para evaluar el tema desde el análisis de constitucionalidad efectuado sobre la base de una interpretación "desde la Constitución y las normas integrantes del parámetro o bloque de constitucionalidad" -reconociéndolos una vez como sinónimos-.

En esta sentencia el Tribunal Constitucional establece que para efectuar una interpretación integral del artículo $74^{\circ}$ de la Constitución referido al ejercicio de la potestad tributaria municipal, debe entenderse que cuando esta norma se refiere a los límites que establece la ley, amplía el parámetro de control constitucional, al ejercicio de la potestad tributaria municipal de tal modo que dicho marco de referencia comprende:

(i) a la Constitución,

(ii) a las normas con contenido material que deriven de ella como la Ley de Tributación Municipal y la Ley Orgánica de Municipalidades en los preceptos referidos a atribuciones y competencias de las municipalidades en el ejercicio de su potestad tributaria ${ }^{32}$, ello en concordancia con el art. 22 de la LOTC -anterior- remitiéndose en su fundamento $14^{\circ}$ a lo ya sostenido en el Exp. Nº07-2002-AI/TC.

\footnotetext{
31 Vid. STC N 1049-2003-AA/TC-LIMA-ETESELVA S.R.L. Fundamento $N^{\circ} 8$.

32 Vid. STC en el Expediente $\mathrm{N}^{\circ}$ 0041-2004-AI/TC-LIMA-DEFENSORÍA DEL PUEBLO, Fundamentos $13^{\circ} \mathrm{y}$ $14^{\circ}$.
} 
Artemio Daniel Meza Hurtado - El denominado bloque de constitucionalidad como parámetro de interpretación constitucional, ¿es necesario en el Perú?

\section{PROBLEMAS EN LA APLICACIÓN DEL PARÁMETRO DE CONSTITUCIONALIDAD}

El bloque de constitucionalidad -se afirma por sus defensores-, representa, como doctrina un avance en la interpretación constitucional de hoy día, puesto que a través de ella se puede ampliar el texto legal más importante de un país como es la Constitución. Su finalidad es la añadir otras fuentes jurídicas del derecho constitucional como es la jurisprudencia, costumbre, tratados internacionales, etc., que ofrezcan un marco más amplio de interpretación que muchas veces es limitada por la rigidez de las Constituciones, pero éste es justamente -creemos- el gran problema para aceptar o no dicha tesis, pues fluyen diversas interrogantes tales como:

- ¿cuáles normas son las que entran a formar el denominado bloque de constitucionalidad?

- ¿las que han sido señaladas como parámetros para apreciar la constitucionalidad de las leyes?

- ¿el artículo $79^{\circ}$ del Código Procesal Constitucional se halla en consonancia con la Constitución?

Al respecto el profesor peruano Domingo GARCÍA BELAÚNDE -probablemente el más versado autor nacional sobre temas constitucionales- ha efectuado una afirmación tajante al comentar sobre la viabilidad de la admisión de la tesis en comento, que "el bloque de constitucionalidad no existe en el Perú"33, la que sustentaba en:

- Que, la Constitución no tiene una sola remisión a otro texto al que incorpore a su mismo nivel y con la misma fuerza vinculante ${ }^{34}$.

- Que por debajo de la Constitución existen leyes, con diverso nombre, pero todas son iguales. No existe una ley superior a otras ni nada que se le parezca.

- Las leyes orgánicas son leyes "comunes y corrientes" ya que lo único que las diferencia de las demás es su contenido específico y el quórum

33 Vid. GARCía Belaúnde, Domingo, op, cit. p. 27, quien afirma comentando el artículo 22 de la anterior Ley Orgánica del TC que: "En el Perú no existe el bloque de constitucionalidad, ya que la Constitución no tiene una sola remisión a otro texto al que incorpore a su mismo nivel y con la misma fuerza vinculante. Porque por debajo de la Constitución existen leyes, con diverso nombre, pero todas son iguales. No existe una ley superior a otras ni nada que se le parezca. Las leyes orgánicas no forman parte de ningún bloque ni ellas constituyen de por sí bloque alguno. Son leyes comunes y corrientes, que lo único que las diferencian es su contenido específico y el quórum para su aprobación. Cualquier ley orgánica y su contenido, pueden ser modificados por cualquier otra ley que de el Congreso, siempre que tenga las características de orgánica".

34 Vid. GARCÍA BELAÚNDE, op. cit. p. 30, quien resalta el hecho que la Constitución vigente a diferencia de la Constitución de 1979, se limita a señalar que los Tratados sobre Derechos Humanos se tomarán en cuenta para interpretar los derechos que la misma consagra. 
Artemio Daniel Meza Hurtado - El denominado bloque de constitucionalidad como parámetro de interpretación constitucional, ¿es necesario en el Perú?

exigido para su aprobación, de esta forma no pueden formar de ningún bloque ni ellas constituyen de por sí bloque alguno.

- Refiriéndose a la anterior Ley Orgánica del Tribunal Constitucional afirmaba que su artículo $22^{\circ}$, al establecer que dicho Tribunal, al momento de resolver la constitucionalidad o inconstitucionalidad, considera las leyes desarrolladas dentro del marco constitucional en materia competencial, es decir con dicho término la norma solo indica que se debe tener en cuenta y servir de referencia, pero no obliga al Tribunal a fallar de acuerdo a esas leyes y en todo caso, no tiene por qué darse un resultado único en las sentencias.

- Que la Jurisprudencia del Tribunal Constitucional jamás ha hecho referencia alguna al concepto de "bloque de constitucionalidad" al que ignora sistemáticamente.

- Que, si ninguna ley es un bloque ni forma parte de un bloque, con mayor razón dicho bloque ni existe ni se extiende a niveles infralegales, como pueden ser los decretos y resoluciones que pudiera dictar el Poder Ejecutivo o las ordenanzas de los gobiernos locales ${ }^{35}$.

Por su parte, los defensores de esta tesis, sostienen que si bien la construcción del bloque de constitucionalidad surgió para dar cuenta de la existencia de un conjunto de normas de igual rango a la Constitución formal, su paulatina recepción, dentro y fuera de Francia, obedece a la necesidad de explicar que el juicio de constitucionalidad a la ley no puede efectuarse únicamente a partir de la Constitución, ya que al haberse establecido en la norma constitucional una pluralidad de órganos con competencias normativas, la misma Carta Magna ha delegado en otras fuentes, de inferior jerarquía a ella, la capacidad para establecer, en su nombre, condiciones y límites al proceso de producción legislativa.

Las normas que integran el bloque de constitucionalidad tendrían un fin netamente instrumental, consistente en describir el conjunto de fuentes que, sumados a la Constitución, pueden actuar como parámetros en los procesos de inconstitucionalidad de las leyes ${ }^{36}$.

Pero surge nuevamente la pregunta ¿es necesario para lograr dicho fin instrumental sacrificar la coherencia de los principios interpretativos que el

\footnotetext{
35 GARCía BELAÚNDE, op. cit. pp. 21-22.

36 Díaz Revorio, Javier, en «¿Puede ser inconstitucional la Constitución?» En materiales de enseñanza para la Maestría en derecho con Mención en Política Jurisdiccional de la PUCP, p. 9 señala "La cuestión de si esa Norma Suprema o Ley Fundamental es válida dependerá naturalmente del concepto de validez utilizado...".
} 
Artemio Daniel Meza Hurtado - El denominado bloque de constitucionalidad como parámetro de interpretación constitucional, ¿es necesario en el Perú?

propio tribunal Constitucional ha ido desarrollando en profusa jurisprudencia (de fuerza normativa, interpretación con la constitución, de coherencia normativa y otros) para introducir un concepto que ni siquiera tiene el mismo significado en el Derecho Constitucional comparado como se puede apreciar de la referencia a los casos de Francia y España?

Pensamos que el Tribunal Constitucional no ha sido coherente ni siquiera con su línea interpretativa en la sentencia comentada, demostrando el inveterado hábito de los operadores jurídicos nacionales de adherir a legislaciones y doctrinas extranjeras sin analizar si conviene o si es necesaria para su aplicación en nuestro país; no obstante lo cual, siendo ya una realidad la posición del máximo intérprete de la Constitución respecto a la adopción del bloque de constitucionalidad -expresada en numerosas resoluciones-, este concepto debe desarrollarse, perfilarse y llenarse de contenido atendiendo a las particularidades de nuestra legislación.

En tal sentido, convenimos con el maestro GARCíA BELAÚNDE con su posición expresada, en el sentido que la aceptación de la tesis del bloque de constitucionalidad si es que va ser aceptada, tiene ser desarrollada por el Tribunal Constitucional pero con las características propias de nuestro ordenamiento jurídico ${ }^{37}$.

\section{CONCLUSIONES}

Primera.- Considero que para establecer finalmente la validez constitucional de las normas cuestionadas de inconstitucionalidad conforme al artículo $79^{\circ}$ del Código Procesal Constitucional, necesariamente el Tribunal Constitucional debe utilizar como parámetros no solo la Constitución Política sino todas las normas que se pueda considerar que componen el marco constitucional interpretativo.

Segunda.- Si bien es cierto, el concepto del bloque de constitucionalidad, tiene origen francés y ha sido utilizado en España con otro significado, en el Perú

\footnotetext{
37 Nos referimos al comentario expresado por GARCíA BELAÚNDE sobre el artículo 22 de la Ley Orgánica del tribunal Constitucional derogada por el Código Procesal Constitucional que ha legislado en su artículo 79 similar texto, por lo que mutatis mutandi el comentario del profesor de la Universidad Católica es válido: El artículo 22 de la Ley Orgánica del Tribunal Constitucional No 26435, señala que dicho Tribunal, al momento de resolver la constitucionalidad o inconstitucionalidad, considera las leyes desarrolladas dentro del marco constitucional en materia competencial. La palabra es considera, es decir, tiene en cuenta y le sirve como referencia. No obliga al Tribunal a fallar de acuerdo a esas leyes, y en todo caso, no tiene por qué darse un resultado único en las sentencias, toda vez que esas leyes de desarrollo constitucional pueden cambiar en cualquier momento.
} 
Artemio Daniel Meza Hurtado - El denominado bloque de constitucionalidad como parámetro de interpretación constitucional, ¿es necesario en el Perú?

existe una posición que la viene desarrollando el Tribunal Constitucional con características propias, interpretación que no puede ser dejada de lado sino desarrollada por todos los operadores jurídicos.

Tercera.- Debe consolidarse una doctrina interpretativa coherente de los principios de interpretación constitucional, para establecer el parámetro de interpretación constitucional incorporando -a la manera de Colombia por ejemplo-, normas obligatorias o vigentes del Derecho Internacional.

Cuarta.- Consideramos que debe incluirse expresamente en la Ley Orgánica del Tribunal Constitucional que las normas integrantes de los Tratados internacionales vigentes en el Perú, son parte integrante del bloque de constitucionalidad que utiliza como parámetro normativo de interpretación el Tribunal Constitucional.

Quinta.- Si bien es cierto es posible que a las normas que integran el parámetro de análisis de constitucionalidad, se le puede designar con otro nombre, existiendo antecedentes de su regulación en otros ordenamientos, como en el caso de Colombia, es conveniente adaptarlo y desarrollarlo con las características específicas nacionales, que posibiliten su aplicación. 
Artemio Daniel Meza Hurtado - El denominado bloque de constitucionalidad como parámetro de interpretación constitucional, ¿es necesario en el Perú?

\section{BIBLIOGRAFÍA}

ARANGO Olaya, Mónica. "El bloque de constitucionalidad en la jurisprudencia de la Corte Constitucional colombiana", en: http://www.icesi.edu.co/ contenido/pdfs/C1C-marango-bloque.pdf

CARPIO MARCOS, Edgar. "Bloque de constitucionalidad y proceso de inconstitucionalidad de las leyes", Conferencia pronunciada en la Facultad de Derecho y Ciencias Políticas de la Universidad Nacional San Cristóbal de Huamanga, en: www.iidpc.org/revistas/4/pdf/93_128.pdf

De CABO DE la VeGA, Antonio. "Nota sobre el bloque de constitucionalidad". Jueces para la democracia, $\mathrm{N}^{\circ}$ 24, Noviembre 1995.

Díaz ZegarRa, Walter. "Comentarios al Código Procesal Constitucional Peruano", Ediciones Legales, Lima 2004.

FAVOREU, Luis. "El bloque de la constitucionalidad", en Revista del Centro de Estudios Constitucionales, Número 5, Enero-marzo 1990, también disponible en: www.cepc.es/rap/Publicaciones/Revistas/15/RCEC_05_043.pdf

García Belaúnde, Domingo. "Estado y Municipio en el Perú", en Anuario de Derecho Constitucional Latinoamericano, Fundación Konrad Adenauer, Montevideo, 2003, disponible en www.garciabelaunde.com/articulos/ EstadoyMunicipio.pdf

MANILI, Pablo. "El ejercicio incompleto del poder constituyente y el bloque de constitucionalidad en España", en Revista Española de Derecho Constitucional, Año 9, $\mathrm{N}^{\circ}$ 27, Setiembre - Diciembre de 1989, también en: www.pablomanili.com.ar/art_ejercicio.doc

Mesía Ramírez, Carlos. "Exégesis del Código Procesal Constitucional", Gaceta Jurídica, Tercera edición, Lima, 2007.

Quiroga LeÓN, Aníbal. “Los excesos del Tribunal Constitucional peruano: a propósito del Control Concentrado de la Constitución", en Estudios Constitucionales, Año 3, N² 2, Universidad de Talca, Chile, 2005.

Requejo Rodríguez, Paloma. "Bloque constitucional y Unión Europea", disponible en: www.acoes.es/congresoVIIIdocumentos/PalomaRequejo.pdf 
Artemio Daniel Meza Hurtado - El denominado bloque de constitucionalidad como parámetro de interpretación constitucional, ¿es necesario en el Perú?

REY CANTOR, Ernesto. "El bloque de constitucionalidad. Aplicación de Tratados Internacionales de Derechos Humanos", en Estudios constitucionales, noviembre, año/vol. 4, número 002. Centro de Estudios Constitucionales, Santiago de Chile, pp.299-234, también accesible en: http.//redalyc.uaemex. $\mathrm{mx}$.

REYES KURI, Juan Fernando. “La inconstitucionalidad de algunas restricciones al derecho a ser elegido en Colombia", Revista de Derecho del Estado $n^{\circ} 23$, diciembre de 2009, en: http:/ / dialnet.unirioja.es/descarga/articulo/3135105. pdf

Riofrío MARTínEZ-VillalbA, Juan Carlos. "El bloque de constitucionalidad pergeñado por el Tribunal Constitucional", en FORO, Revista de Derecho, No. 6, UASB-Ecuador/CEN. Quito, 2006.

RUBio LloRENTE, Francisco. "El bloque de constitucionalidad", en Revista española de Derecho Constitucional, Año 9, Núm. 27. Septiembre-Diciembre 1989, y en: dialnet.unirioja.es/servlet/articulo?codigo=79403

Ruiz MolLEDA, Juan Carlos y Luis Andrés Roel Alva. “Tribunal Constitucional aplica analógicamente normas procesales de manera cuestionable". Disponible en: http://www.justiciaviva.org.pe/webpanel/doc_trabajo/doc17062009131058.pdf

Rueda Aguilar, Dolores. "El bloque de constitucionalidad en el sistema colombiano", consultar en: https://www.scjn.gob.mx/Transparencia/Lists/ Becarios/Attachments/88/Becarios_088.pdf

UPRIMNY, Rodrigo. "Bloque de constitucionalidad, Derechos Humanos y nuevo procedimiento penal", en: http://www.wcl.american.edu/humright/ hracademy/documents/Clase1-Lectura3BloquedeConstitucionalidad.pdf

\section{JURISPRUDENCIA}

Sentencia de la Corte Constitucional de Colombia del 04 de febrero de 2003, número C-067/03, tema: Demanda de inconstitucionalidad contra el artículo 21(parcial) de la Ley 734 de 2002. Nuevo Código Disciplinario -Tratados internacionales sobre Derechos Humanos - uso directo de la normatividad del bloque de constitucionalidad. 